Research Article

\title{
Viscoelastic Equivalent Creep Behavior and Its Influencing Factors of Basalt Fiber-Reinforced Asphalt Mixture under Indirect Tensile Condition
}

\author{
Xiaoyuan Zhang ${ }^{(D,},{ }^{1}$ Yu Zhang, ${ }^{2}$ Yichun $W u,{ }^{2}$ and Peng Xia ${ }^{1}$ \\ ${ }^{1}$ School of Civil Engineering and Architecture, Zhejiang Sci-Tech University, Hangzhou 310018, China \\ ${ }^{2}$ Zhejiang Communication Construction Group Co.,Ltd., Hangzhou 310051, China \\ Correspondence should be addressed to Xiaoyuan Zhang; xyzhang@zstu.edu.cn
}

Received 1 December 2020; Revised 29 January 2021; Accepted 3 February 2021; Published 17 February 2021

Academic Editor: Jinyang Xu

Copyright (c) 2021 Xiaoyuan Zhang et al. This is an open access article distributed under the Creative Commons Attribution License, which permits unrestricted use, distribution, and reproduction in any medium, provided the original work is properly cited.

\begin{abstract}
The aim of this study is to further investigate the effect of different basalt fiber (BF) factors on the viscoelastic equivalent creep behavior of fiber-reinforced asphalt mixture (FRAM) under indirect tensile (IDT) condition. A two-dimension mesostructural model composed of different components including fiber mortar polymer and coarse particle aggregate is constructed via the section image processing for the IDT FRAM specimen, where BF is considered as random distribution in the mortar polymer. Furthermore, the stress distribution and equivalent creep of the IDT mesostructural model in simulation software are analyzed to discuss the influence of components on the creep behavior of FRAM. Moreover, the laboratory creep test of IDT specimens under $0 \%$ and $0.3 \% \mathrm{BF}$ contents for FRAM is carried out to validate the simulated values. Research results indicate that the simulated creep deformation of the IDT mesostructural model is in agreement with that of the experiment. Finally, creep simulations are further conducted to discuss the effect of BF (e.g., fiber content, length-diameter ratio, and fiber modulus) and aggregate on the creep characteristic of FRAM. The increase of fiber content and length-diameter ratio has a significant reinforcing effect on the equivalent mechanical behavior, but the change in the modulus of fiber and aggregate has slight effects.
\end{abstract}

\section{Introduction}

Adding fibers into asphalt mixture has been studied increasingly [1-6]. For example, Chen et al. [3] investigated the effect of four different fibers including lignin, polyester, asbestos, and polyacrylonitrile fibers on the mechanical and volumetric properties of asphalt mixture and proposed a materials design procedure of fiber-reinforced asphalt mixture (FRAM). Liu and $\mathrm{Wu}$ [4] evaluated the stability of graphite and carbon fiber modified asphalt mixture by a series of laboratory tests. Testing results indicated that their Marshall stability and rutting dynamic stability improved by approximately $5.5 \%$ and $2.6 \%$, respectively. Guo et al. [5] investigated the compound modified influence of diatomite and glass fiber on the antirutting performance of asphalt mixture. The results indicated that the high-temperature property of asphalt mixture was improved greatly. Hong et al. [6] researched the pavement performance of polyester fiber added into asphalt mixture through the semicircular bending (SCB) test under low temperature conditions, and the results indicated that the crack resistance of asphalt mixture with the $0.4 \%$ optimum fiber content at $-20^{\circ} \mathrm{C}$, $-10^{\circ} \mathrm{C}$, and $0^{\circ} \mathrm{C}$ increased by about $45.9 \%, 37.3 \%$, and $36.6 \%$, respectively.

Basalt fiber (BF) in asphalt mixture has also been compared with some common fiber modifiers [7-11]. For instance, $\mathrm{BF}$ has more superior mechanical property and durability than organic fibers and is also more eco-friendly than glass and steel fibers [12-16]. Morova [7] evaluated the influence of $\mathrm{BF}$ content on the pavement stability of asphalt 
mixture by the Marshall stability test, and $0.5 \%$ fiber content could significantly enhance the materials stability. Cheng et al. [9] studied the characteristics of BF modified asphalt mixture via a series of tests, and the results indicated that the FRAM produced more superior performances compared with that of nonfiber asphalt mixture. Wang et al. [10] researched the damage characteristic of asphalt mixture modified with BF after freeze-thaw cycles using the indirect tensile (IDT) test, and the testing results indicated that the modified asphalt mixture had better mechanical characteristics. Guo et al. [17] researched the modes I and II fracture properties of BF-reinforced asphalt mixture through the SCB test, and results showed that BF could soundly enhance the critical fracture energy of asphalt mixture at medium and low temperature, where the reinforcing effect of $\mathrm{BF}$ was optimal for the mixed mode fracture.

However, although macroscopic performance of adding fibers into asphalt mixture had been recognized, investigation on the inner action mechanism of FRAM considering IDT condition is still limited. Therefore, exploring the mesostructural structure of asphalt mixture composed of the different mesoscopic components is necessary to better investigate the action effect of fibers. Many researchers have researched the mechanical properties of asphalt mixture through combining the detection technology of the mixture's mesostructure with the numerical approach to build the quantitative relationship of the mesoscopic characteristics to mixture macroscopic responses [18-22]. For example, Kose et al. [18] obtained the section's mesostructure of the asphalt mixture specimen via image processing, and the mechanical responses of the mesostructural specimen and its macroscopic characteristics for dense gradation asphalt mixture were simulated and analyzed through the finite element (FE) software. In addition, Buttlar and You [19] investigated the mesostructural characteristics of the SMA mixture specimen and then built the mesostructural specimen model in the discrete element software. Finally, the mechanical responses were successfully obtained. Birgisson et al. [20] collected mesostructural characteristic of dense gradation asphalt mixture and then simulated the action mechanism of cracking by using the boundary element approach. Wang [21] obtained the two-dimension (2D) microstructure of asphalt mixture by CT scanning of IDT specimens, thereby clarifying the relationship between mesoscopic components by using the FE mesostructural simulation. Zhang and Liu [22] obtained the mesostructure of SCB specimens by $2 \mathrm{D}$ scanning and image processing technology and simulated the bending creep of the asphalt mixture specimen model by the FE method to discuss and analyze the influence of the mesoscopic components on the macroscopic creep response.

Furthermore, as a typical composite, the macroscopic properties of asphalt mixture depend on its components characteristics and mesostructure, particularly on polymer matrix and its distribution in asphalt mixture [23, 24]. The influence of short fiber on the characteristic of polymer materials in asphalt mixture has been widely reported [25-29]. As a matrix material, asphalt mortar polymer is part of a lower scale of asphalt mixture that consists of bitumen polymer, mineral powder, and fine particle aggregate. It exhibits a complex mechanical behavior influencing the macroscopic properties of asphalt mixture. Adding fiber into asphalt mixture can enhance the viscoelastic behavior of the mortar polymer material to optimize the macroscopic performance (i.e., stability, anticrack, and fatigue) of asphalt mixture significantly [30-32]. For instance, the results of experiment and simulation indicated that mortar polymer materials having BF can present superior performance in the aspect of stability, durability, and strength [33, 34]. Zhang et al. [33] established a three-dimension (3D) mesoscopic model of $\mathrm{BF}$ distribution in the asphalt mortar beam specimen to explore the influence of fiber (i.e., directional and random distribution) on the bending creep characteristic of the mortar polymer material, and the simulated results of the 3D model were validated via corresponding creep experiments. Zhang et al. [34] further considered the effect of other BF factors (i.e., content, length-diameter ratio, and modulus) on the bending creep characteristic of mortar polymer based on the 3D mesoscopic model and established the correlation equations between fiber factors and viscoelastic parameters for asphalt mortar.

The research indicates that limited work has used multiscale mesostructural simulations to analyze and discuss the influence of fiber parameters on the viscoelastic equivalent creep characteristic of asphalt mixture under indirect tensile condition. Thus, further studying the influence of the mesostructural components on the viscoelastic equivalent creep behavior of FRAM is necessary to reveal the action mechanism on the basis of the existed mesostructural models.

\section{Objective}

The aim of this study is to determine the influence of mesoscopic components, such as BF short fiber, mortar polymer, and coarse particle aggregate, on the viscoelastic equivalent creep behavior of BF-reinforced asphalt mixture (BFRAM). The main contents are shown as follows:

(1) A 2D mesostructural specimen model of asphalt mixture consists of two components, i.e., BF mortar polymer and coarse particle aggregate, which are established by section scanning of the IDT specimens for AC13 gradation, where $\mathrm{BF}$ is considered randomly distributed in the viscoelastic mortar polymer.

(2) IDT creep tests of the BFRAM specimens on the basis of the developed typical 2D mesostructural model are simulated and analyzed by FE software, and the obtained results and testing datum are compared. Then, the effect of components on the BFRAM is discussed at a constant temperature.

\section{Materials and Methods}

3.1. Materials. Asphalt mixture specimens of AC13 dense gradation in the superpave gyratory compactor were molded, where the optimum oil-stone ratio in asphalt mixture was $4.9 \%$. The testing values of gradation are listed in Table 1. 
TABLE 1: Gradation of AC13 asphalt mixture.

\begin{tabular}{|c|c|c|c|c|c|c|c|c|c|c|}
\hline \multirow{2}{*}{ Sieve size $(\mathrm{mm})$} & \multicolumn{10}{|c|}{ Pass weight percentage } \\
\hline & 16 & 13.2 & 9.5 & 4.75 & 2.36 & 1.18 & 0.6 & 0.3 & 0.15 & 0.075 \\
\hline Lower limit & 100 & 90 & 68 & 38 & 24 & 15 & 10 & 7 & 5 & 4 \\
\hline Testing value & 100 & 98.2 & 78.1 & 46.8 & 35.2 & 26.2 & 18.4 & 12.9 & 10.2 & 7.9 \\
\hline Upper limit & 100 & 100 & 85 & 68 & 50 & 38 & 28 & 20 & 15 & 8 \\
\hline
\end{tabular}

The SBS-modified bitumen of PG76-22 grade and limestone mineral powder were selected in asphalt mixture, and the characteristics of these raw materials satisfy the requirements of the specifications of JTG E42-2005 and JTG E202011 standards of China $[35,36]$. Furthermore, fine and coarse aggregates adapted the limestone and basalt ore, respectively, and the corresponding boundary value between the nominal maximum and minimum aggregate particles was $2.36 \mathrm{~mm}$.

Mortar polymer consisted of bitumen, mineral powder, and fine particle aggregate; it was prepared in agreement with the standard of JTG F40-2004 of China [33, 34, 37]. Moreover, the oil-stone ratio of corresponding mortar polymer was $13.0 \%$, which was obtained by the design of the specific surface area method [33,34]. Table 2 presents the gradation values of mortar polymer.

Two BF contents in asphalt mixture including $0 \%$ and $0.3 \%$ were selected for testing, where the length and diameter of fiber was $6 \mathrm{~mm}$ and $0.02 \mathrm{~mm}$, respectively. The physical characteristics of BF are listed in Table 3.

\subsection{Testing and Simulation Methods}

3.2.1. Creep Tests of the IDT Specimen. The diameter of $100 \mathrm{~mm}$ and thickness of $30 \mathrm{~mm}$ for the IDT specimens were selected. In the UTM-25 temperature-controlled loading test machine, the material testing system, head loading type, and vertical displacement data output at the pressure head in the IDT loading test are similar to the SCB test [22]. Moreover, the test loading device and IDT specimen can be seen in Figure 1, where the width of the upper and lower head devices is $12.7 \mathrm{~mm}$. For the loading process of specimens, the $2 \%$ predetermined load is maintained at 60 s initially to allow the specimens to fully connect to the head devices. Then, the predetermined load is maintained to $1800 \mathrm{~s}$ to carry out the creep test under the constant loads.

In accordance with the width of the pressure head and size of the IDT specimen, combined with the reference code of [36], the calculation formula of each index for IDT specimen can be obtained when the specimen's thickness $T$ and vertical load $P$ are known as follows:

$$
\begin{aligned}
\sigma_{t} & =0.006249 \frac{P}{T}, \\
\sigma_{c} & =-0.019022 \frac{P}{T}, \\
X_{T} & =Y_{T} \frac{0.135+0.5 \mu}{1.794-0.0314 \mu},
\end{aligned}
$$

TABLE 2: Gradation of corresponding AC13 mortar polymer [34].

\begin{tabular}{lcccccc}
\hline \multirow{2}{*}{ Sieve size $(\mathrm{mm})$} & 1.18 & 0.6 & 0.3 & 0.15 & 0.075 & $<0.075$ \\
\hline Values & 25.6 & 22.2 & 15.6 & 7.7 & 6.5 & 22.4 \\
\hline & \\
$\varepsilon_{t}$ & $=X_{T} \frac{0.0307+0.0936 \mu}{1.35+5 \mu}$, \\
$S_{T}$ & $=P \times \frac{0.27+\mu}{T \times X_{T}}$, \\
$J_{T}$ & $=\frac{T \times X_{T}}{P \times(0.27+\mu)}$,
\end{tabular}

where $X_{T}$ and $Y_{T}$ denote the horizontal and vertical deformation through the specimen center, respectively, $\mathrm{mm} ; \sigma_{t}$ and $\sigma_{c}$ express the horizontal tensile stress and vertical compressive stress at the section's central position of the specimen, respectively, $\mathrm{MPa} ; \varepsilon_{t}$ denotes the horizontal tensile strain at the section's central position of the specimen; $\mu$ expresses Poisson's ratio; $S_{T}$ denotes the stiffness modulus of the material, MPa; and $J_{T}$ denotes the creep compliance, $1 / \mathrm{MPa}$.

3.2.2. FE Simulation of the Homogeneous IDT Specimen. To analyze the stress distribution of the homogeneous IDT specimen under the vertical force control, a reasonable simulation loading should be set. In this regard, the rigid body pressure heads of $12.7 \mathrm{~mm}$ width at the top and bottom of the $2 \mathrm{D}$ specimen model were set to bind the IDT specimen. Then, the reference point was set at the rigid body pressure heads to load a vertical concentrated force at the top head and apply constraint at the bottom head to simulate the loading situation of the IDT model. In this model, the unit type adopted the quadrilateral element and the meshing density was $2 \mathrm{~mm}$. Stress contours of the IDT model in each direction can be obtained, as listed in Figure 2.

\subsubsection{Control Stress of the Homogeneous IDT Specimen.} To verify the accuracy of the simulation results, the simulated value at the center of the specimen was compared with the analytical solution. The stress at the section's central position of the specimen is only affected by the principal stress in the $X$ and $Y$ axes. Thus, the analytical solutions of tensile and compressive stress can be obtained according to formulas (1) and (2), respectively, which can be compared with the numerical simulation values. Furthermore, on the 
TABle 3: Physical characteristics of BF.

\begin{tabular}{lcccc}
\hline Index & Tensile strength $(\mathrm{MPa})$ & Density $\left(\mathrm{g} / \mathrm{cm}^{3}\right)$ & Elastic modulus $(\mathrm{GPa})$ & Elongation $(\%)$ \\
\hline Values & $450 \times 10^{1}$ & 2.70 & 100 & 3.10 \\
\hline
\end{tabular}

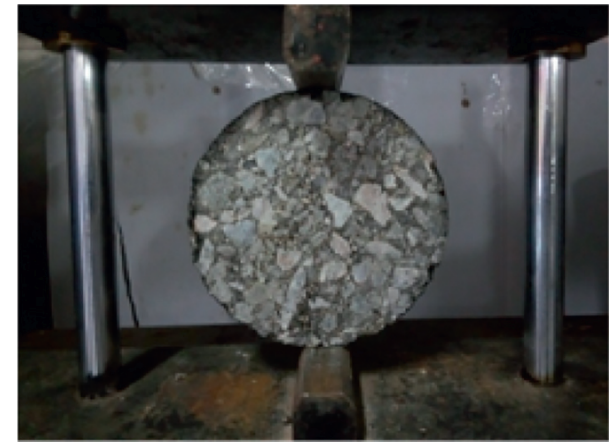

FIgURE 1: Creep loading for IDT specimen.

basis of the stress state of a certain point, the Mises equivalent stress can be obtained as follows:

$$
\sigma_{\text {eq }}=\frac{1}{\sqrt{2}} \sqrt{\left(\sigma_{1}-\sigma_{2}\right)^{2}+\sigma_{1}^{2}+\sigma_{2}^{2}}
$$

Then, in accordance with the stress state at the center of the IDT specimen, $\sigma_{1}=\sigma_{t}$ and $\sigma_{2}=\sigma_{c}$ can be obtained. Equations (1) and (2) are substituted into (7), and the equivalent stress calculation formula at the center of the IDT specimen can be obtained as follows:

$$
\sigma_{\text {eq, mises }}=0.0227985 \frac{P}{T},
$$

with the $P$ of $10.1 \mathrm{~N}$ per unit thickness as an example; the simulated results of tensile stress, compressive stress, and Mises equivalent stress at the control point of the IDT specimen center were $0.0594,0.1832$, and $0.219 \mathrm{MPa}$, respectively. Meanwhile, according to formulas (1), (2), and (8), the corresponding stresses at this control point were $0.063 \mathrm{MPa}, 0.192 \mathrm{MPa}$, and $0.230 \mathrm{MPa}$, respectively. Thus, compared with the analytical solution, the errors of the simulation results were controlled within $5.7 \%, 4.8 \%$, and $4.78 \%$; it also indicated that the FE numerical simulation of the IDT specimen model was reasonable.

3.3. Mesostructural Simulation of BFRAM. The viscoelastic behavior of BFRAM is further studied by FE creep simulation of the IDT mesostructural specimen model on the basis of the $2 \mathrm{D}$ mesoscopic modeling and constitutive behavior of fiber mortar polymer in $[33,34]$. Furthermore, the influence of the mesostructural components on the macroscopic performance of asphalt mixture was investigated to illustrate the relationship of fiber mortar polymer to the corresponding mixture.

The mesostructural components of BFRAM include BF, mortar polymer, and coarse particle aggregate. Nevertheless, the multiphase modeling is difficult to carry out in the mesoscopic scale. Therefore, this investigation only focuses on a two-phase composite mixture composed of coarse particle aggregate (no less than $2.36 \mathrm{~mm}$ ) and mortar polymer and then combined with the research results of $\mathrm{BF}$ modified mortar polymer in [34] to establish the mesoscopic structure model of BFRAM. Hence, the mesoscopic modeling of the actual mixture consisting of BF mortar polymer and aggregate was introduced, and then corresponding simulation and experimental verification were completed.

3.3.1. Modeling of IDT Mesostructural Specimens. BFRAM for AC13 gradation was selected to mold a cylindrical IDT specimen, and then the IDT specimen was cut into many circular sections. In addition, to distinguish the surface color difference between aggregate and mortar components before the section image scanning, white chalk was applied to paint the aggregate component in the circular sections.

The circular sections of the IDT specimen were scanned by a $2 \mathrm{D}$ scanner to obtain actual section images. Moreover, the processing of each image among obtained scanning sections was further carried out. The main steps are as follows:

(1) Pretreatment

Prior to implementing the edge detection, the pretreatment of the scanning section image was conducted by MATLAB software, where the median filter approach was adopted to reduce the image noise.

(2) Edge detection

Edge detection is a key step for image processing and a basic reflection of image grayscale discontinuity. In the processing, detection threshold can be dynamically adjusted on the basis of the processing results of each step to get sufficient details for components distribution. This investigation mainly refers to the image processing approach of [22] adopted to process the two-phase composite mesostructure containing aggregate and mortar polymer matrix. The binary section images with aggregate boundary were obtained. In addition, the adhesion problem between aggregate edges in the binary images was solved via an approach of corrosion or expansion. Furthermore, the area ratios of mesoscopic components in the circular section image close to the designed volume ratios in the IDT specimen were selected as the typical mesostructural model. The schematic diagrams of the binary section image for the IDT specimen are presented in Figure 3.

(3) Geometry vectorization

After the above binary mesostructural model was built, it must be vectorized to be used in the 


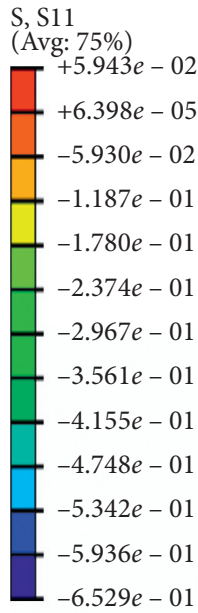

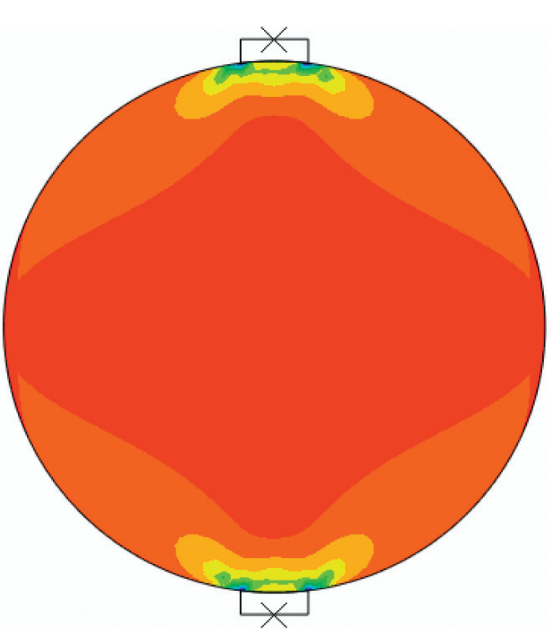

(a)

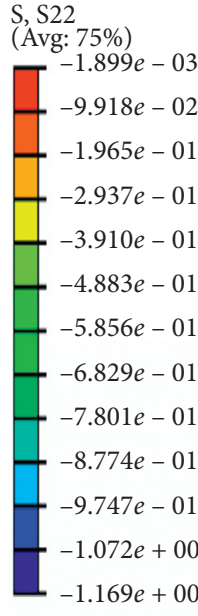

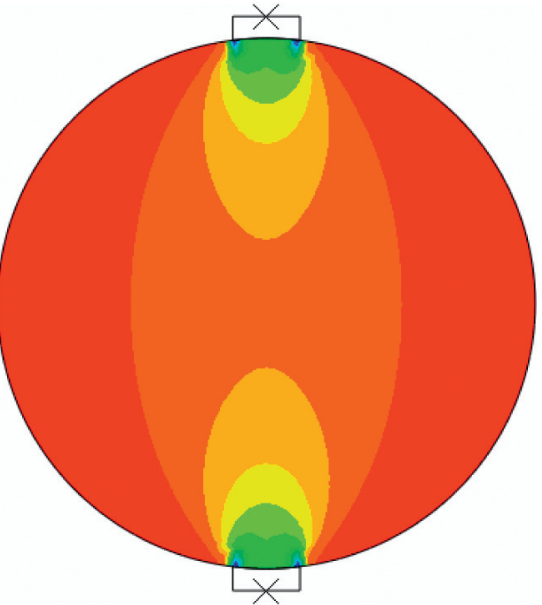

(b)
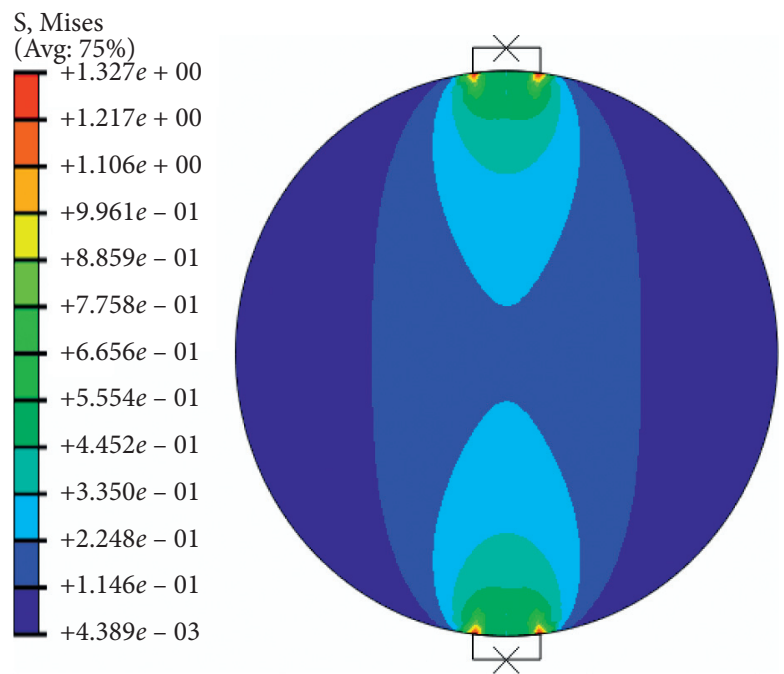

(c)

Figure 2: Stress contours of the IDT homogeneous model. (a) $S_{11}$ stress. (b) $S_{22}$ stress. (c) Mises stress.

mesomechanical simulation. Therefore, the binary section images need to be further processed by the image vector software to get a vectorized format file, which can be imported into ABAQUS simulation software for the $2 \mathrm{D}$ numerical model.

3.3.2. Numerical Simulation of IDT Mesostructural Specimens. Section scanning and image processing of the IDT specimens were carried out by the above modeling method to obtain the $2 \mathrm{D}$ mesostructure numerical models for given $\mathrm{AC} 13$ gradation, as presented in Figure 4.

Furthermore, the material parameter setting, meshing, and element types for the IDT mesostructural specimen model in the creep simulation process are the same as those of the SCB mesostructural specimen model [22]. For example, the material constitutive properties of aggregate and mortar polymer were set as linear elasticity and viscoelasticity, respectively, where Poisson's ratio and elastic modulus for aggregate were $50 \mathrm{GPa}$ and 0.25. In addition, the parameters of the selected Burgers model for mortar polymer are listed in Table 4 and corresponding values were obtained on the basis of $[33,34]$.

In the FE simulation, the contact relation of aggregate to mortar polymer was considered to be completely continuous. For the mesh type of mortar polymer and aggregate, the former was blended with quadrilateral and triangle modes, and the latter was selected as a triangle mode, where the adaptive meshing algorithm was adopted and the global seed density was $2 \mathrm{~mm}$. Meanwhile, the reference points RP- 1 and RP-2 were set at the pressure head of the IDT mesostructural specimen model. Then, considering vertical force or vertical displacement added at the point RP-1 as the load control quantity, the macroscopic response quantity obtained at this point as the verification index can be compared with the 


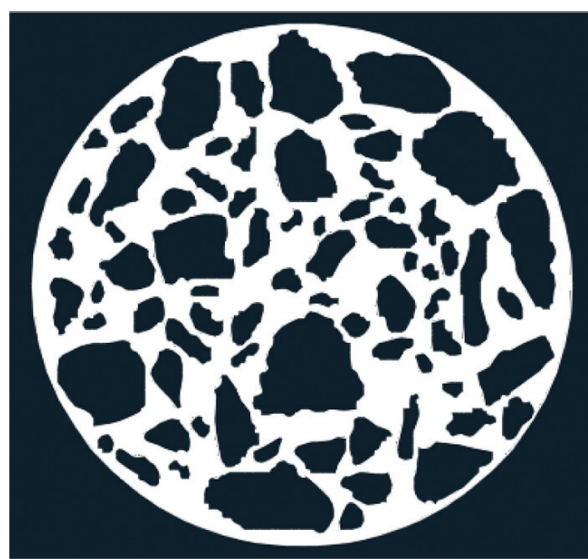

(a)

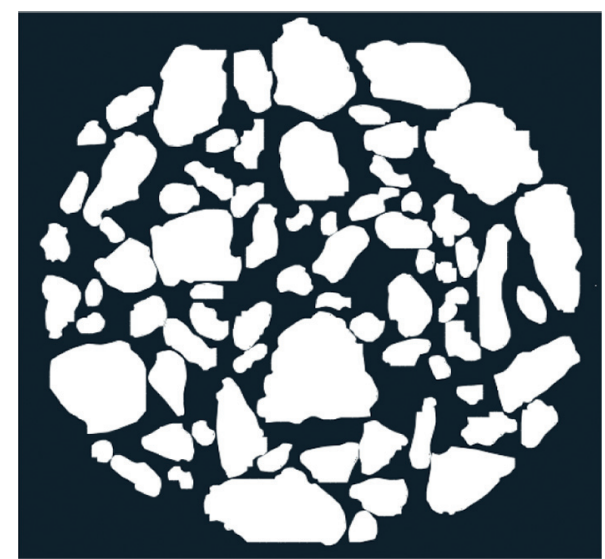

(b)

Figure 3: Schematic diagram of the binary section image for IDT specimens. (a) Distribution of asphalt mortars. (b) Distribution of coarse aggregates.

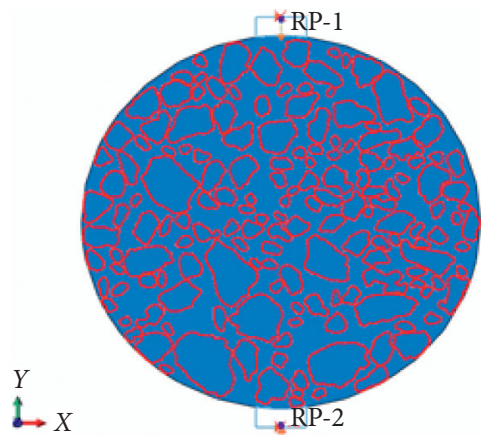

FIGURE 4: IDT mesostructural specimen model.

TABLE 4: Constitutive parameters of mortar polymer.

\begin{tabular}{lcccccccc}
\hline \multirow{2}{*}{ Material types } & \multicolumn{9}{c}{ Constitutive parameters } \\
& $E_{1}$ & $E_{2}$ & $\eta_{1}$ & $\eta_{2}$ & $g_{1}$ & $g_{2}$ & $\tau_{1}$ \\
\hline Control & 16.6 & 4.82 & $157 \times 10^{2}$ & $237 \times 10^{1}$ & 0.81 & 0.19 & 102 \\
BF & 26.1 & 12.3 & $469 \times 10^{2}$ & $578 \times 10^{1}$ & 0.71 & 0.29 & 143 & $596 \times 10^{1}$ \\
\hline
\end{tabular}

experiment values. When the vertical force $P$ of per unit thickness is $10.1 \mathrm{~N}$, the different stress contours of the IDT mesostructural specimen model can be obtained (seen in Figure 5).

The comparison between Figures 2 and 5 shows that the stress gradient of the homogeneous IDT specimen changes significantly, and the stress of the mesostructural specimen presents a redistribution phenomenon. In addition, to illustrate the similarities and differences between the homogeneous and mesostructural specimen models, the specific stress values on the vertical $Y$ symmetry axe passing through the specimen center are obtained (see Figure 6). The figure indicates that the overall stress variation trend of the two types of specimen models under the same vertical force is similar, and it also indicates that the numerical simulation of the mesostructural specimen is reasonable. In addition, the stress distribution of the mesostructural model presents the phenomenon of stress concentration and mutation; thus, it has evident nonuniformity characteristics.
To obtain the macroscopic mechanical properties of the mesostructural specimen model consisting of mortar polymer matrix and coarse particle aggregate and to establish the relationship of the mesoscopic components to the macroscopic mechanical properties, the viscoelastic creep simulation of the heterogeneous specimen model was carried out. The contour of the simulated vertical creep displacement during $1800 \mathrm{~s}$ is shown in Figure 7.

Moreover, to further verify the parameter setting rationality of the composition characteristics of the mesostructural IDT specimen, the vertical displacement $Y_{T}$ at the reference point RP-1 of the IDT model in Figure 7 is extracted, and then the creep compliance $J_{T}$ can be obtained by formulas (3) and (6). Meanwhile, the equivalent stress under a given load can be calculated by formula (8). Finally, the equivalent strain $\varepsilon_{\mathrm{eq}}$ of the control point at the center of the IDT model can be obtained in accordance with the equivalent stress multiplied by the creep deformation $J_{T}$ as follows: 


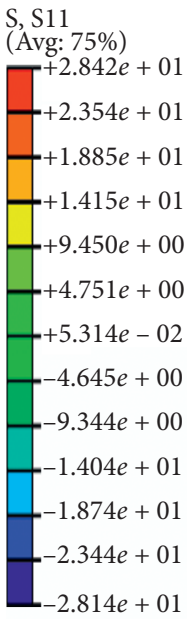

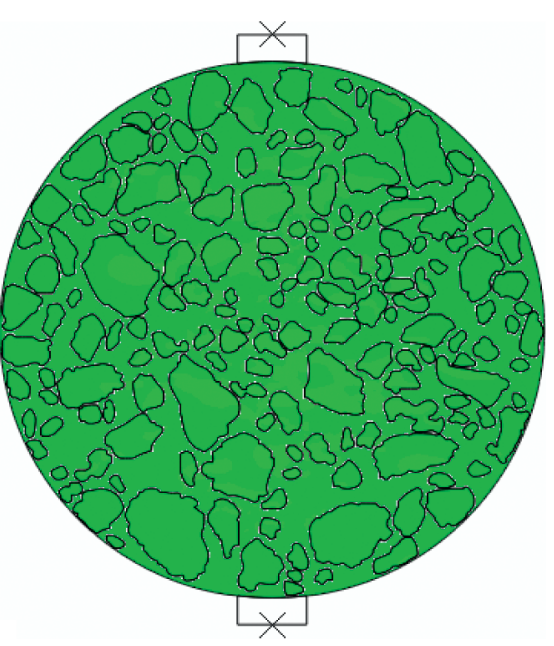

(a)

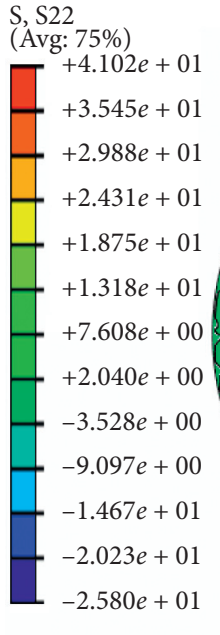

S, Mises

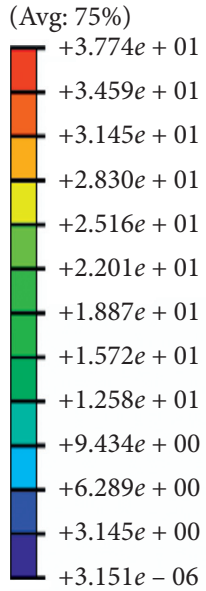

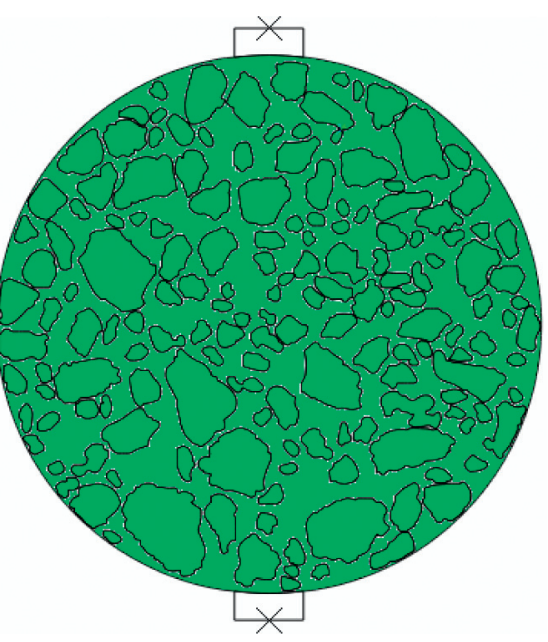

(b)

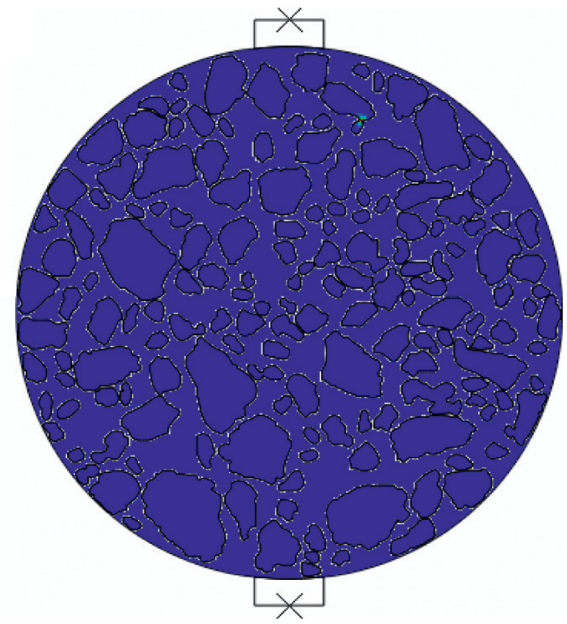

(c)

Figure 5: Different stress contours of the IDT mesostructural model. (a) $S_{11}$ stress. (b) $S_{22}$ stress. (c) Mises stress.

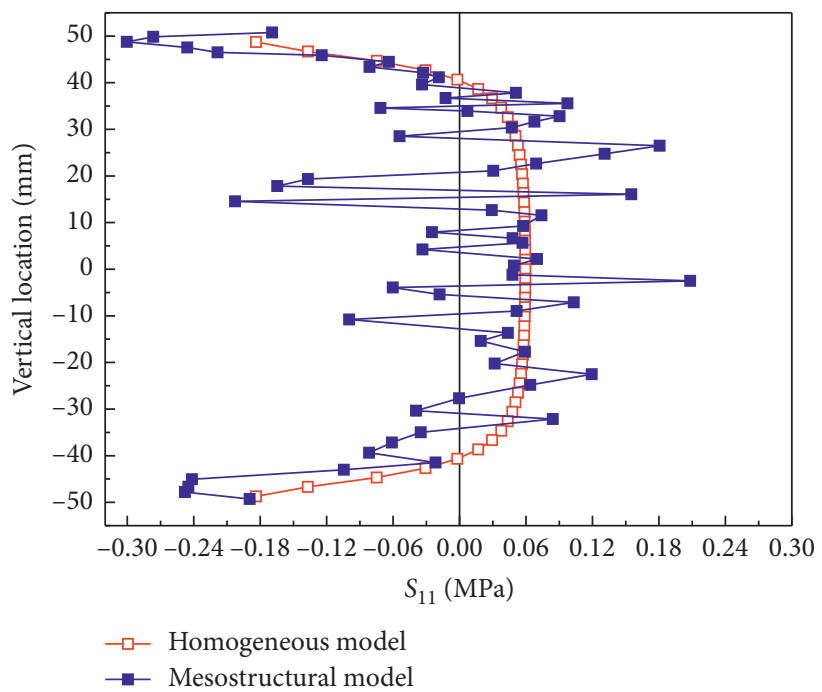

(a)

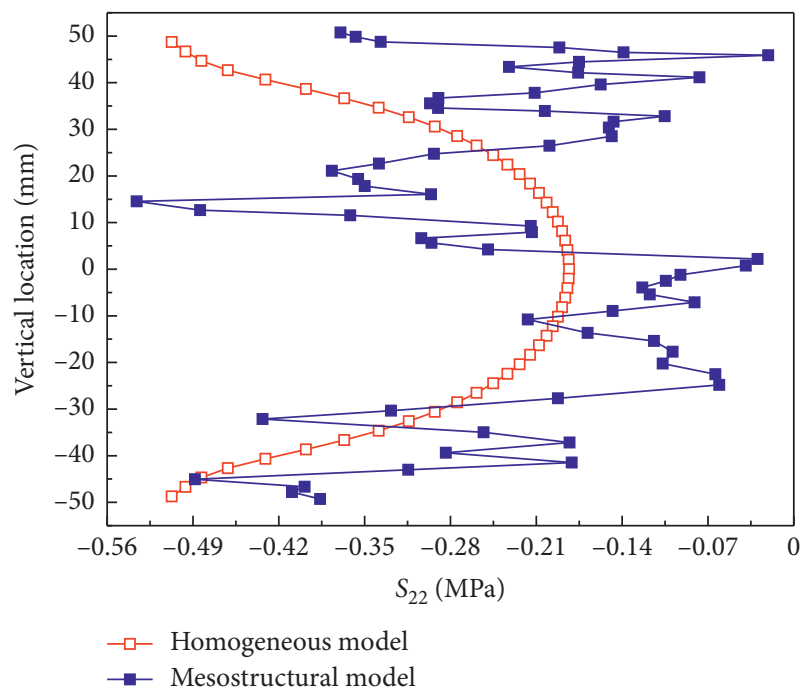

(b)

Figure 6: Stress distribution of two IDT models on the vertical symmetry axis. (a) $S_{11}$ stress. (b) $S_{22}$ stress. 

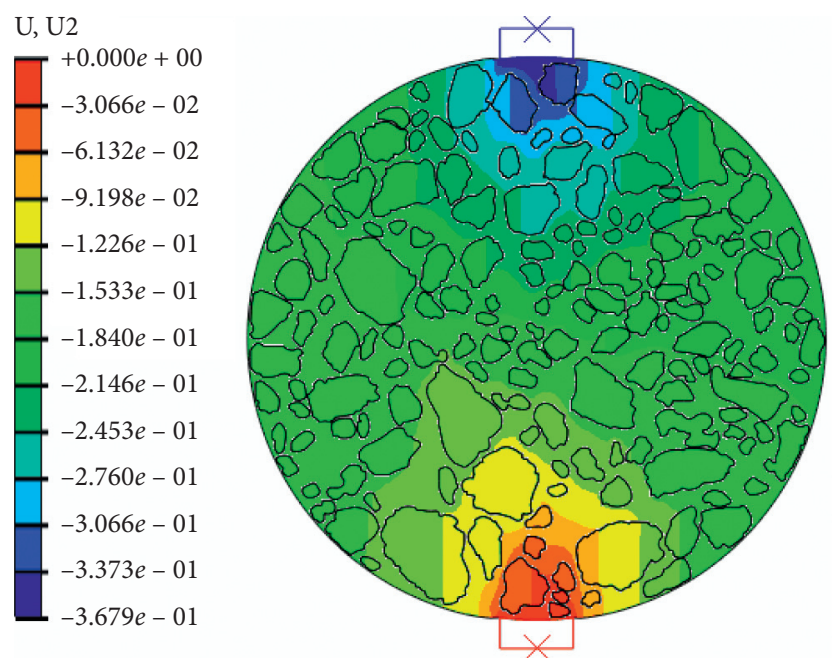

Figure 7: Vertical displacement contours of the IDT mesostructural model at $1800 \mathrm{~s}$.

$$
\varepsilon_{\mathrm{eq}}=0.0227985 \frac{Y_{T}}{(0.27+\mu)} .
$$

The vertical displacement at the top head and the equivalent strain at the central control point of the specimen on the basis of the results in Figure 7 and formula (9) are shown in Figure 8 . The curves in Figure 8 show that the simulated value obtained on the basis of the mesoscopic specimen is close to the laboratory test value. This finding also indicates that the mesoscopic component parameters and the specimen's mesoscopic image processing are reasonable and feasible. Furthermore, the viscoelastic characteristic parameters of asphalt concrete under IDT test can be obtained by calculating the viscoelastic equivalent strain of the central control point of specimens.

\section{Results and Discussion}

The equivalent creep behavior and some influencing factors of BFRAM were further analyzed and discussed through the simulation of the IDT mesostructural specimen model and combining with the validation of corresponding experiments.

4.1. Effect of BF Mortar Polymer. For the performance effect of adding BF fiber asphalt mixture, the numerical simulation method of the mesostructural IDT specimen model was adopted. In this regard, the effect of the fiber added into asphalt mixture was initially considered on the basis of the characteristics of mortar polymer. Then, the influence of the macroscopic performance of asphalt mixture consisting of mortar polymer and coarse particle aggregate can be further studied.

For the simulated viscoelastic creep of the BFRAM specimen, the vertical displacement contour of the IDT specimen under $0.3 \% \mathrm{BF}$ contents is obtained by applying the $10.1 \mathrm{~N}$ vertical load of per unit thickness, as shown in Figure 9. Furthermore, the equivalent viscoelastic strain at

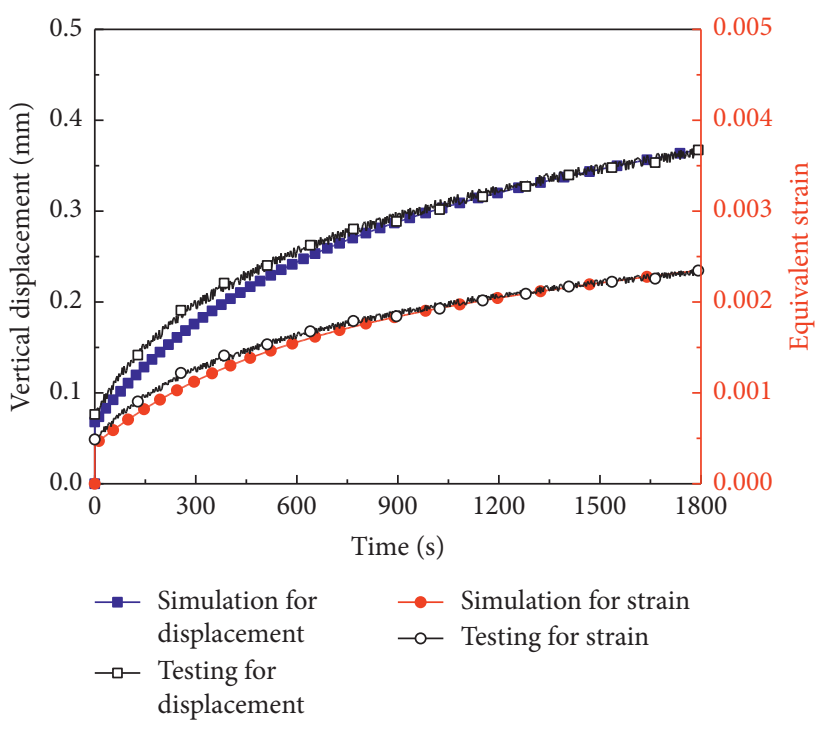

FIgURE 8: Equivalent creep deformation of the IDT specimen at control points.

the central point of the specimens with and without fiber can be calculated by formula (9), as shown in Figure 10. The results show that, compared with the equivalent viscoelastic strain of the control specimens, the creep value of the fiber added to the specimen decreased significantly. The strain value decreased by approximately $37.2 \%$ at $1800 \mathrm{~s}$. The finding also indicates that the BF-reinforced asphalt mixture had a significant effect. In addition, the numerical simulation results are consistent with those of the laboratory test, thereby verifying the validity of the IDT mesoscopic specimen model.

Meanwhile, to better understand the internal mechanism of BFRAM, the stress field of the IDT mesostructural specimen was further simulated and analyzed. Figure 11 shows the Mises equivalent stress contour of the local area in the center of the simulated specimen, and two element nodes (No. 776 and 7937) were selected as examples.

The microstructure of a representative typical gradation was adopted in this study; that is, the mesoscopic structure of asphalt mixture under the same gradation is unchanged and adding fiber into asphalt mixture can be regarded as a modification of the properties of asphalt mortar. The results in literature [34] showed that the fiber positively affects the resistance rheological deformation of asphalt mortar. Thus, the modulus of fiber mortar polymer is higher than that of no fiber mortar. As shown in the equivalent stress contour in Figure 11, the stress value of the fiber mortar component for the BFRAC specimen is larger than that of the control specimen. In addition, the overall modulus of the specimen increased and the ability of resisting deformation improved. Hence, the modification effect of the fiber at the macroscopic scale of asphalt mixture is easy to understand.

4.2. Sensitivity Analysis of Constitutive Parameters for BFRAM. The viscoelastic equivalent strain curves of the control and BFRAM were fitted to obtain the constitutive parameters of the Burgers model on the basis of the 

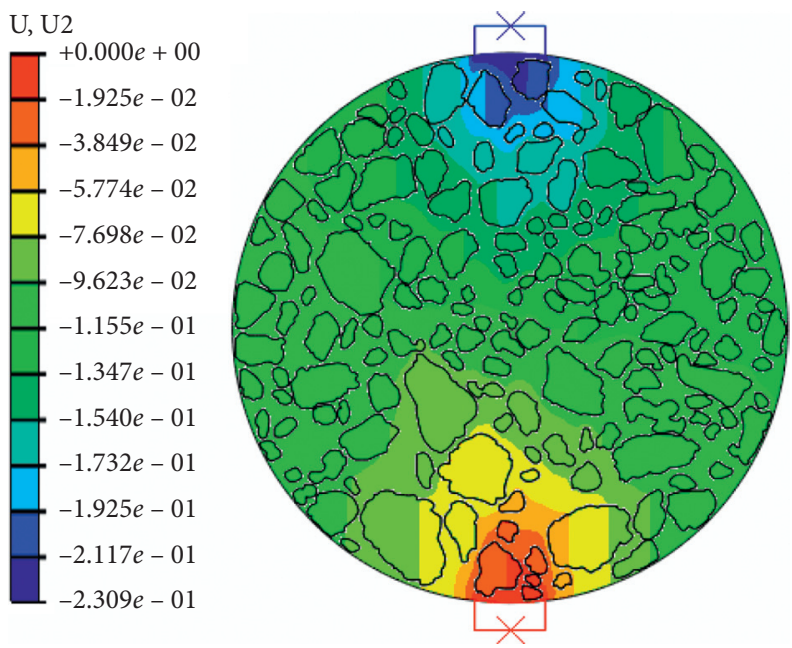

FIgURE 9: Vertical creep displacement contours under $0.3 \%$ BF contents at $1800 \mathrm{~s}$.

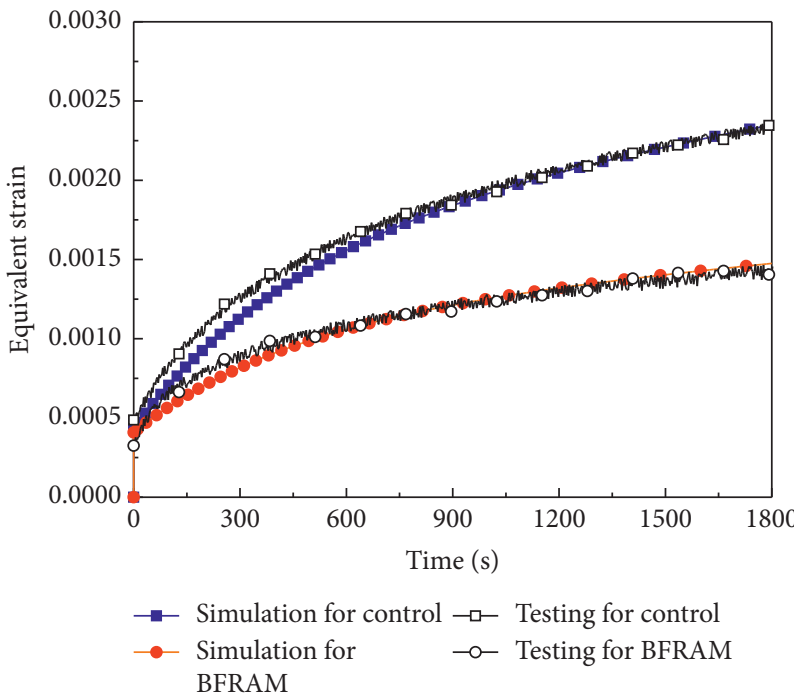

FIgURE 10: Equivalent creep deformation under $0 \%$ and $0.3 \%$ BF contents at control points.

simulated results of the IDT mesostructural specimen model. The results of the viscoelastic parameters are presented in Table 5.

The effect of components on the equivalent creep behavior of BFRAM was further studied by the method of the mesoscopic simulation and macroscopic test validation. The IDT mesostructural specimen model under AC13 gradation was adopted to discuss the influence of aggregate and fiber (e.g., BF content, modulus, and length-diameter ratio) on the constitutive parameters [34].

4.2.1. Effect of Aggregate Modulus. To study the effect of aggregate on the viscoelastic equivalent characteristic of asphalt mixture, the aggregate modulus of 40,50 , and $60 \mathrm{GPa}$ was set to simulate the viscoelastic equivalent creep for the nonfiber asphalt mixture, and the calculated results of the constitutive parameters are presented in Figure 12.
The change in the relationship in Figure 12 indicates that the change in the aggregate modulus slightly influences the viscoelastic parameters, such as the maximum values of $E_{1}$, $E_{2}, \eta_{1}$, and $\eta_{2}$, compared with the corresponding minimum values, only increased by about $0.60 \%, 0.18 \%, 0.08 \%$, and $0.28 \%$, respectively. Hence, when the gradation of BFRAM is determined, the influence effect of aggregate modulus in the IDT specimen mixture cannot be considered.

4.2.2. Effect of Fiber Parameters. The influence of fiber factors on the variation of four parameters is shown in Figure 13, where different fiber contents are considered under $100 \mathrm{GPa}$ fiber modulus and 30 fiber length-diameter ratios. In addition, fiber modulus is selected under $0.3 \%$ fiber contents and 30 fiber length-diameter ratios; fiber lengthdiameter ratio is considered under $100 \mathrm{GPa}$ fiber modulus and $0.3 \%$ fiber contents. This finding indicates that, 


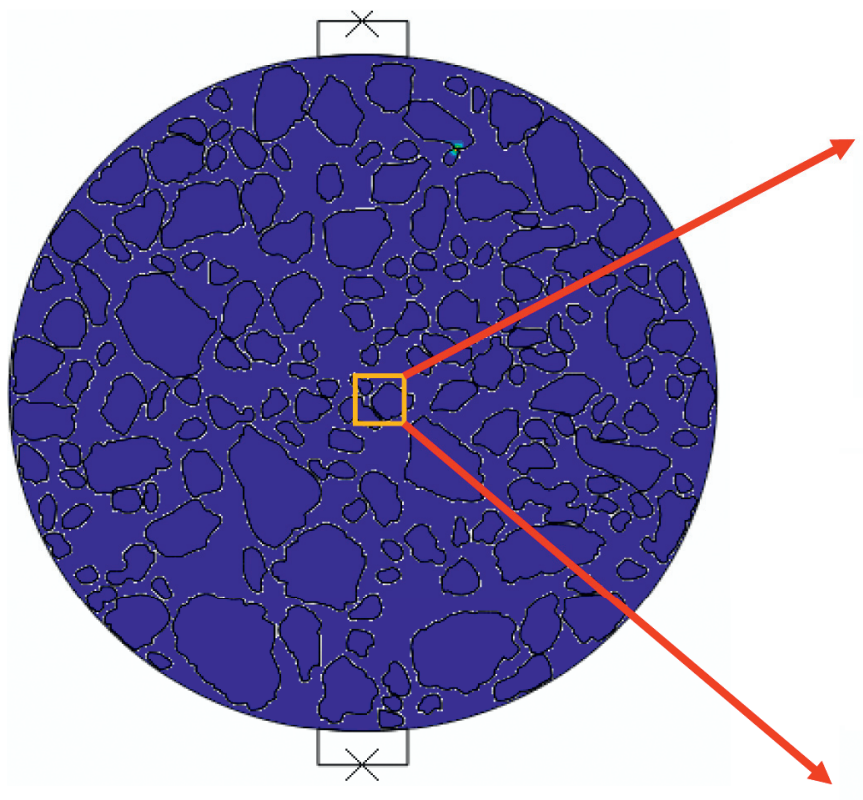

S, Mises
(Avg: $75 \%$ )

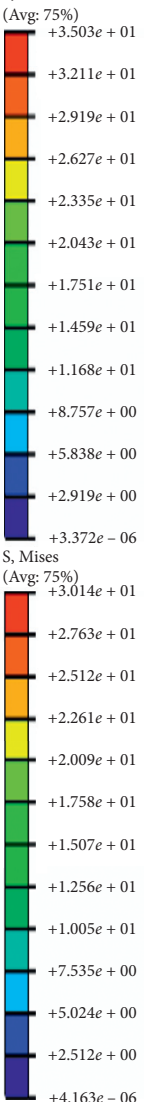

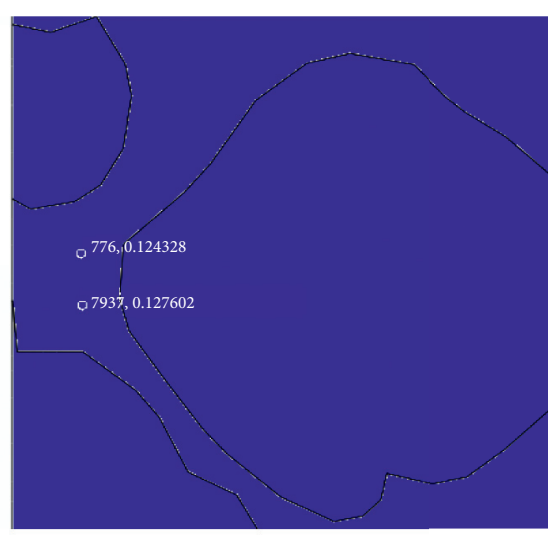

(a) Control

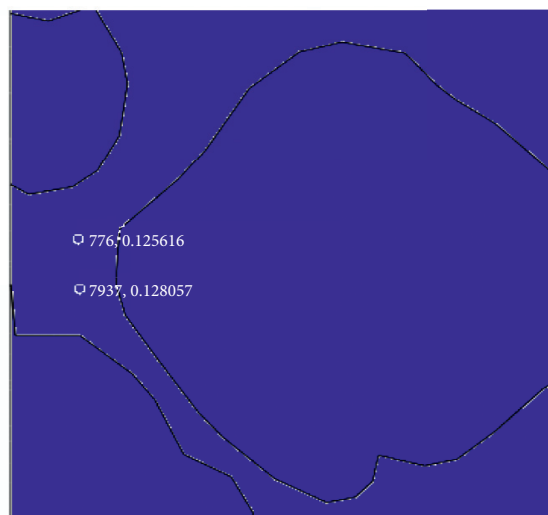

(b) BFRAM

FIgURE 11: Equivalent stress of the mesostructural model at 1800 s. (a) $0 \%$ BF content; (b) $0.3 \%$ BF contents.

TABLE 5: Viscoelastic constitutive parameters of BFRAM under IDT condition.

\begin{tabular}{lcccc}
\hline \multirow{2}{*}{ BF contents (\%) } & \multicolumn{4}{c}{ Constitutive parameters of BFRAM } \\
& $E_{1}$ & $\eta_{1}$ & $E_{2}$ & $\eta_{2}$ \\
\hline 0 & 542 & 566133 & 189 & 86595 \\
0.3 & 577 & 954430 & 313 & 122171 \\
\hline
\end{tabular}

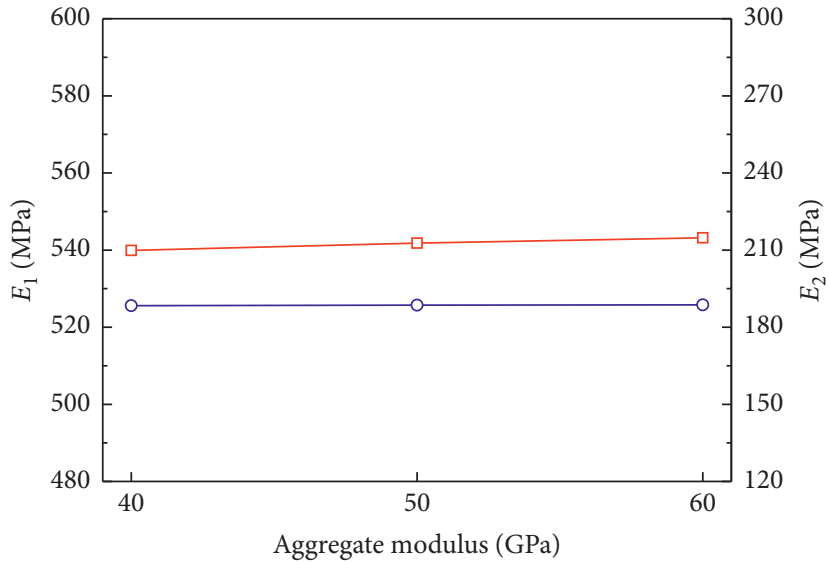

$-\square-E_{1}$

$\multimap E_{2}$

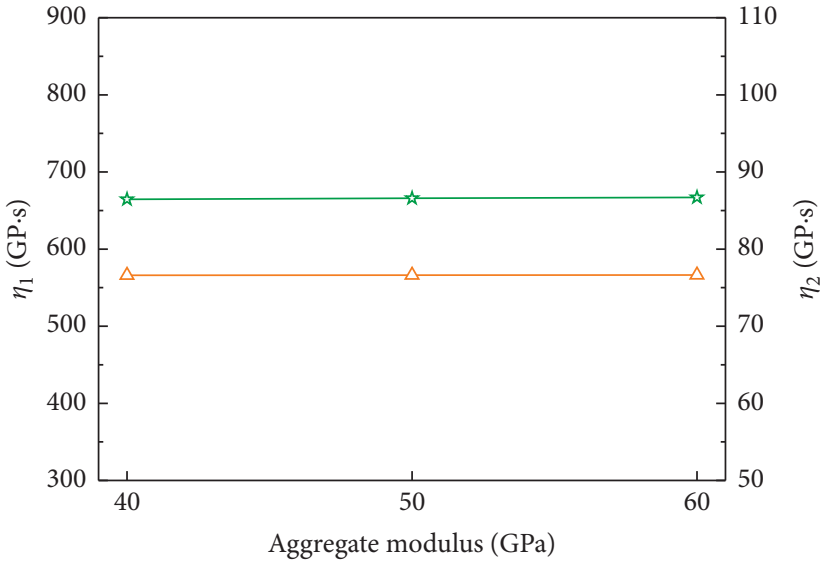

$-\triangle \eta_{1}$

$\rightarrow \eta_{2}$

(a)

(b)

FIGURE 12: Relationship between aggregate modulus and constitutive parameters for asphalt mixture. (a, b) Aggregate modulus. 

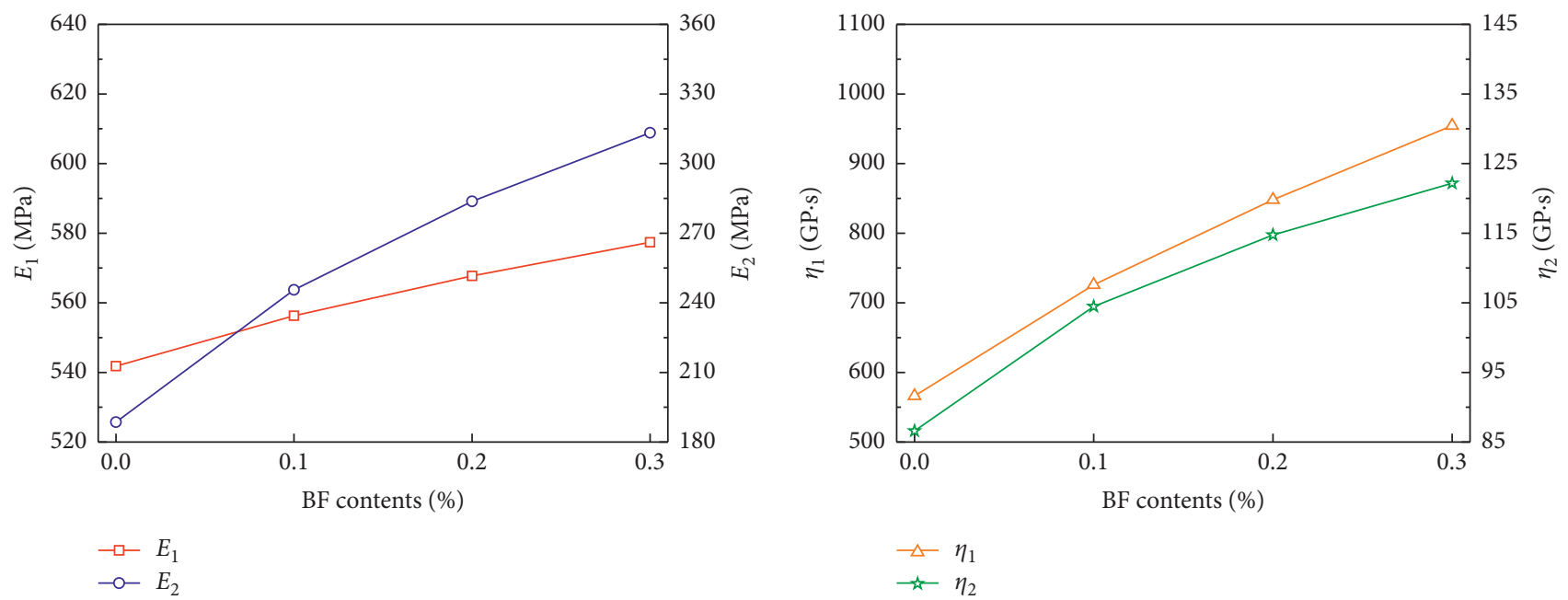

(a)

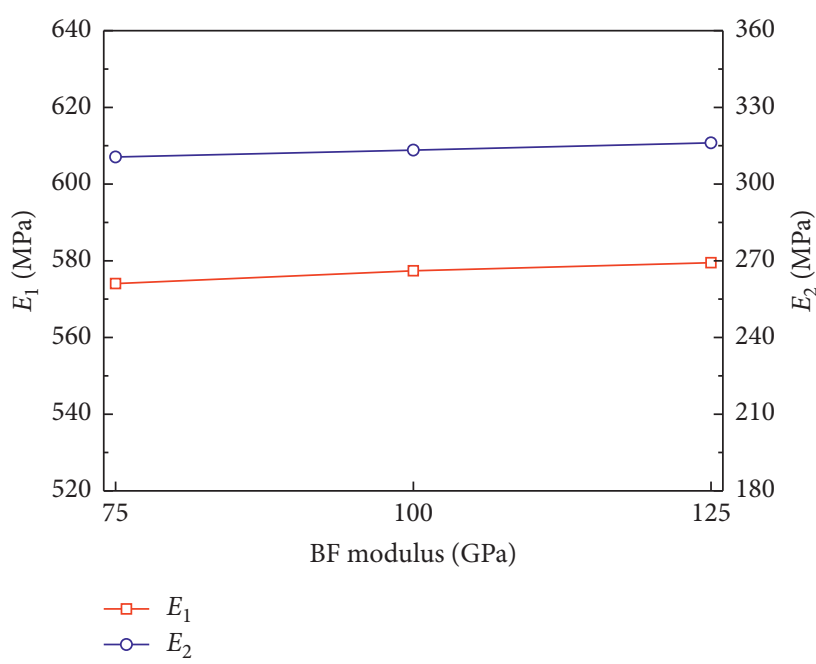

(c)

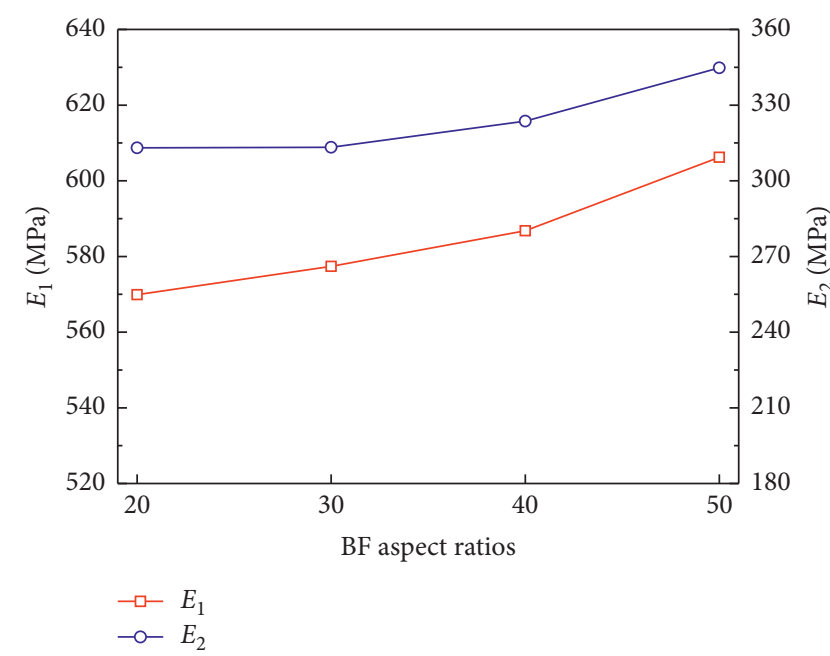

(e)

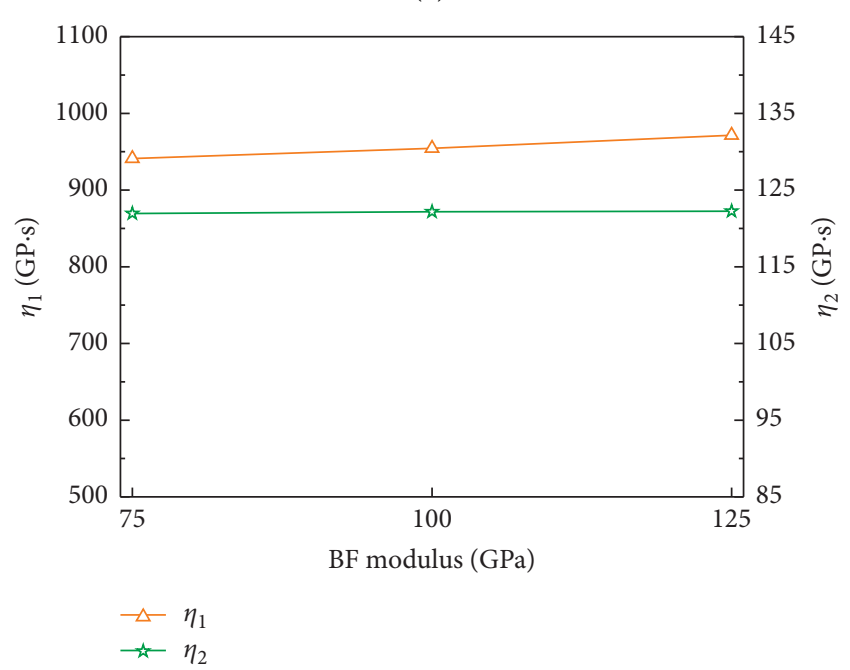

(d)

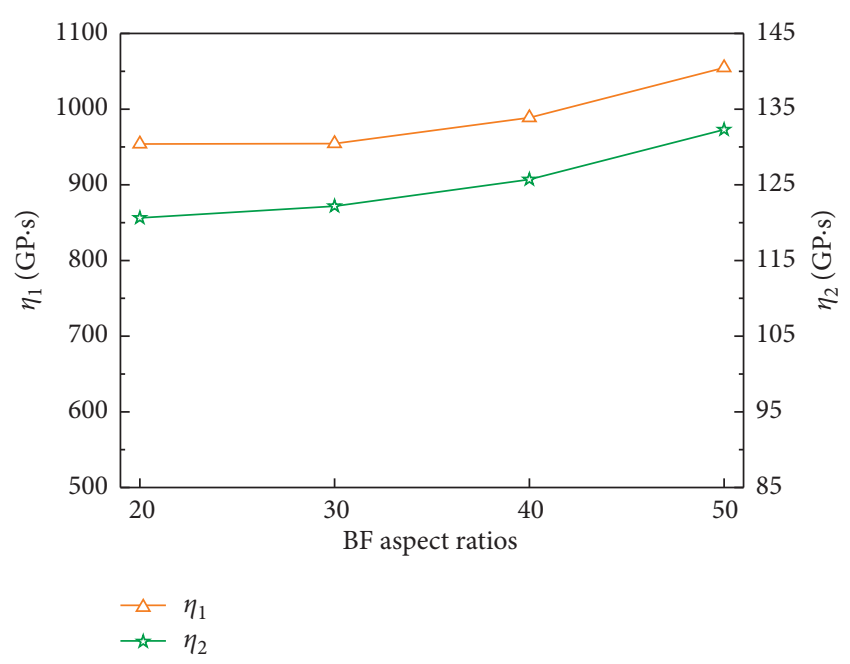

(f)

FIGURE 13: Relationship between fiber and constitutive parameters for asphalt mixture. (a) BF contents. (b) BF contents. (c) BF modulus. (d) BF modulus. (e) BF aspect ratios. (f) BF aspect ratios. 
compared with the sensitivity of fiber content and lengthdiameter ratio on viscoelastic four parameters, the variation of fiber modulus at the macroscopic level of asphalt mixture slightly influences the parameters, where the maximum values of $E_{1}, E_{2}, \eta_{1}$, and $\eta_{2}$, compared with the corresponding minimum values, only increased by about $0.95 \%, 1.79 \%$, $3.23 \%$, and $0.25 \%$, respectively. Therefore, when the gradation is determined, the influence in fiber modulus in BFRAM can also be ignored; that is, only the sensitivity analysis of fiber content and length-diameter ratio on the four parameters is considered. In addition, the parameters of asphalt mixture increase with the increase in fiber content and length-diameter ratio, where the maximum values of $E_{1}$, $E_{2}, \eta_{1}$, and $\eta_{2}$, compared with the corresponding minimum values, increased by approximately $6.56 \%, 66.1 \%, 68.6 \%$, and $41.1 \%$ under different fiber contents, respectively. The values increased by approximately $6.37 \%, 10.1 \%, 10.6 \%$, and $9.66 \%$ under different fiber length-diameter ratios. Therefore, fiber content and length-diameter ratio are the main factors for the effect of the viscoelastic creep behavior of BFRAM under IDT condition.

\section{Conclusions}

The viscoelastic equivalent creep behavior of BFRAM is mainly studied on the basis of the mesostructural simulation of the IDT specimen model, consisting of BF mortar polymer and coarse particle aggregate and the validation of the macroscopic test. The main conclusions can be drawn as follows:

(1) Mechanical analysis of the mesostructural and homogeneous models shows that the overall trend of stress distribution in the symmetry axis is close. However, the stress distribution of the two models also has significant differences. The homogeneous model has evident gradient change, and the mesostructural model has the stress concentration and mutation phenomenon. Moreover, the local stress of the mesostructural model at the central control point is different from the homogeneous model.

(2) Results of viscoelastic equivalent creep deformation at the control point of the mesostructural model indicate that, compared with the control model under $0 \% \mathrm{BF}$ content, the equivalent strain of BFRAM under $0.3 \% \mathrm{BF}$ contents is significantly reduced by $37.2 \%$ at $1800 \mathrm{~s}$. The results also indicate that the BFRAM had a significant reinforcement effect. In addition, the simulation results are consistent with those of the laboratory test, thereby verifying the validity of the IDT mesostructural specimen model.

(3) On the basis of the simulated equivalent creep results of the IDT mesostructural specimen model, the effects of aggregate modulus, fiber content, modulus, and length-diameter ratio on the viscoelastic parameters of Burgers model for BFRAM are further analyzed. Results indicated that, compared with the influences of fiber content and length-diameter ratio, the effect of aggregate and fiber modulus on the viscoelastic parameters can be ignored. The effect of fiber content and length-diameter ratio on viscoelastic parameters increases with the increase in the two fiber factors.

\section{Data Availability}

The data used to support the findings of this study are included within the article.

\section{Conflicts of Interest}

The authors declare no conflicts of interest.

\section{Acknowledgments}

This investigation was supported by the Natural Science Foundation of Zhejiang Province (Grant no. LQ19E080025), Science Foundation of Zhejiang Sci-Tech University (Grant no. 18052139-Y), Science and Technology Project of the Communications Department of Zhejiang Province (Grant no. 2020013), and First-Class Disciplines Project of Civil Engineering in Zhejiang Province.

\section{References}

[1] S. M. Abtahi, M. Sheikhzadeh, and S. M. Hejazi, "Fiberreinforced asphalt-concrete-a review," Construction and Building Materials, vol. 24, no. 6, pp. 871-877, 2010.

[2] C. J. Slebi-Acevedo, P. Lastra-González, P. Pascual-Muñoz, and D. Castro-Fresno, "Mechanical performance of fibers in hot mix asphalt: a review," Construction and Building Materials, vol. 200, pp. 756-769, 2019.

[3] H. Chen, Q. Xu, S. Chen, and Z. Zhang, "Evaluation and design of fiber-reinforced asphalt mixtures," Materials \& Design, vol. 30, no. 7, pp. 2595-2603, 2009.

[4] X. Liu and S. Wu, "Study on the graphite and carbon fiber modified asphalt concrete," Construction and Building Materials, vol. 25, no. 4, pp. 1807-1811, 2011.

[5] Q. Guo, L. Li, Y. Cheng, Y. Jiao, and C. Xu, "Laboratory evaluation on performance of diatomite and glass fiber compound modified asphalt mixture," Materials \& Design, vol. 66, pp. 51-59, 2015.

[6] R. Hong, J. Wu, and H. Cai, "Low-temperature crack resistance of coal gangue powder and polyester fibre asphalt mixture," Construction and Building Materials, vol. 238, pp. 1-13, 2020.

[7] N. Morova, "Investigation of usability of basalt fibers in hot mix asphalt concrete," Construction and Building Materials, vol. 47, no. 10, pp. 175-180, 2013.

[8] X. Gu, X. Zhang, and J. Lv, "Laboratory performance evaluation of reinforced basalt fiber in sealing asphalt chips," Journal of Testing and Evaluation, vol. 46, no. 3, pp. 12691279, 2017.

[9] Y. Cheng, D. Yu, Y. Gong, C. Zhu, J. Tao, and W. Wang, "Laboratory evaluation on performance of eco-friendly basalt fiber and diatomite compound modified asphalt mixture," Materials, vol. 11, no. 12, p. 2400, 2018.

[10] W. Wang, Y. Cheng, and G. Ma, "Further investigation on damage model of eco-friendly basalt fiber modified asphalt mixture under freeze-thaw cycles," Applied Sciences, vol. 9, no. 1, p. 60, 2019. 
[11] L. Liu, Z. Liu, and J. Liu, "Effects of silane-coupling agent pretreatment on basalt fibers: analyzing the impact on interfacial properties and road performance," Journal of Materials in Civil Engineering, vol. 32, no. 4, Article ID 04020041, 2020.

[12] M. Wang, Z. Zhang, and Y. Li, "Chemical durability and mechanical properties of alkali-proof basalt fiber and its reinforced epoxy composites," Journal of Reinforced Plastics and Composites, vol. 27, no. 4, pp. 393-407, 2008.

[13] D. Wang, L. Wang, X. Gu, and G. Zhou, "Effect of basalt fiber on the asphalt binder and mastic at low temperature," Journal of Materials in Civil Engineering, vol. 25, no. 3, pp. 355-364, 2013.

[14] C. Ralph, P. Lemoine, J. Summerscales, E. Archer, and A. McIlhagger, "Relationships among the chemical, mechanical and geometrical properties of basalt fibers," Textile Research Journal, vol. 89, no. 15, pp. 3056-3066, 2019.

[15] W. Wang, Y. Cheng, and G. Tan, "Design optimization of SBS-modified asphalt mixture reinforced with eco-friendly basalt fiber based on response surface methodology," Materials, vol. 11, no. 8, p. 1311, 2020.

[16] Y. Huang, Z. Liu, L. Liu, Y. Zhang, and Q. Xu, "Hybrid modification of stone mastic asphalt with cellulose and basalt fiber," Advances in Materials Science and Engineering, vol. 2020, Article ID 5671, 11 pages, 2020.

[17] Q. Guo, Z. Chen, P. Liu et al., "Influence of basalt fiber on mode I and II fracture properties of asphalt mixture at medium and low temperatures," Theoretical and Applied Fracture Mechanics, vol. 112, Article ID 102884, 2021.

[18] S. Kose, M. Guler, H. U. Bahia, and E. Masad, "Distribution of strains within hot-mix asphalt binders: applying imaging and finite-element techniques," Transportation Research Record: Journal of the Transportation Research Board, vol. 1728, no. 1, pp. 21-27, 2000.

[19] W. G. Buttlar and Z. You, "Discrete element modeling of asphalt concrete: microfabric approach," Transportation Research Record: Journal of the Transportation Research Board, vol. 1757, no. 1, pp. 111-118, 2001.

[20] B. Birgisson, C. Soranakom, J. A. L. Napier, and R. Roque, "Microstructure and fracture in asphalt mixtures using a boundary element approach," Journal of Materials in Civil Engineering, vol. 16, no. 2, pp. 116-121, 2004.

[21] H. N. Wang, Study on the Microstructure and Numerical Simulation of Asphalt Mixture, Chang'an University, Xi'an, China, 2007, in Chinese.

[22] X. Zhang and J. Liu, "Viscoelastic creep properties and mesostructure modeling of basalt fiber-reinforced asphalt concrete," Construction and Building Materials, vol. 259, pp. 1-13, 2020.

[23] R. Lackner, M. Spiegl, R. Blab, and J. Eberhardsteiner, "Is lowtemperature creep of asphalt mastic independent of filler shape and mineralogy?-arguments from multiscale Analysis," Journal of Materials in Civil Engineering, vol. 17, no. 5, pp. 485-491, 2005.

[24] C. Wu, L. Li, W. Wang, and Z. Gu, "Experimental characterization of viscoelastic behaviors of nano- $\mathrm{TiO}_{2} / \mathrm{CaCO}_{3}$ modified asphalt and asphalt mixture," Nanomaterials, vol. 11, no. 1, p. 106, 2021.

[25] P. S. Kandhal, C. Y. Lynn, and F. Parker, "Characterization tests for mineral fillers related to performance of asphalt paving mixtures," Transportation Research Record: Journal of the Transportation Research Board, vol. 1638, no. 1, pp. 101110, 1998.
[26] K. S. Bonnetti, K. Nam, and H. U. Bahia, "Measuring and defining fatigue behavior of asphalt binders," Transportation Research Record: Journal of the Transportation Research Board, vol. 1810, no. 1, pp. 33-43, 2002.

[27] Y.-R. Kim, D. H. Allen, and D. N. Little, "Computational constitutive model for predicting nonlinear viscoelastic damage and fracture failure of asphalt concrete mixtures," International Journal of Geomechanics, vol. 7, no. 2, pp. 102-110, 2007.

[28] Y. Miao, T. Wang, and L. Wang, "Influences of interface properties on the performance of fiber-reinforced asphalt binder," Polymers, vol. 11, no. 3, p. 542, 2019.

[29] W. Wang, Y. Cheng, P. Zhou, G. Tan, H. Wang, and H. Liu, "Performance evaluation of styrene-butadiene-styrene-modified stone mastic asphalt with basalt fiber using different compaction methods," Polymers, vol. 11, no. 6, p. 1006, 2019.

[30] S. Tayfur, H. Ozen, and A. Aksoy, "Investigation of rutting performance of asphalt mixtures containing polymer modifiers," Construction and Building Materials, vol. 21, no. 2, pp. 328-337, 2007.

[31] S. Tapkın, "The effect of polypropylene fibers on asphalt performance," Building and Environment, vol. 43, no. 6, pp. 1065-1071, 2008.

[32] Q. Xu, H. Chen, and J. A. Prozzi, "Performance of fiber reinforced asphalt concrete under environmental temperature and water effects," Construction and Building Materials, vol. 24, no. 10, pp. 2003-2010, 2010.

[33] X. Zhang, X. Gu, and J. Lv, "Effect of basalt fiber distribution on the flexural-tensile rheological performance of asphalt mortar," Construction and Building Materials, vol. 179, pp. 307-314, 2018.

[34] X. Zhang, L. Xu, and J. Lv, "Investigation on the flexuraltensile rheological behavior and its influence factors of fiberreinforced asphalt mortar," Polymers, vol. 12, no. 9, p. 1970, 2020.

[35] Standard JTG E42-2005, Test Methods of Aggregate for Highway Engineering, China Communications Press, Beijing, China, 2005, in Chinese.

[36] Standard JTG E20-2011, Standard Test Methods of Bitumen and Bituminous Mixtures for Highway Engineering, China Communications Press, Beijing, China, 2011, in Chinese.

[37] Standard JTG F40-2004, Technical Specifications for Construction of Highway Asphalt Pavements, China Communications Press, Beijing, China, 2004, in Chinese. 